\title{
The role of parental control and coping strategies on adolescents' problem behaviors
}

\author{
Cristiano Inguglia ${ }^{1}$ (D) - Sebastiano Costa $^{2} \cdot$ Sonia Ingoglia ${ }^{1} \cdot$ Francesca Cuzzocrea $^{3} \cdot$ Francesca Liga $^{4}$
}

(C) Springer Science+Business Media, LLC, part of Springer Nature 2020

\begin{abstract}
The current study was aimed at contributing to the understanding of the role of perceived parental monitoring, psychological control, and coping strategies on adolescents' problem behaviors, in terms of anxiety and drinking behavior. Participants were 541 high school students, 17 to 19-year old $(M=17.09, S D=0.80)$ high school students in Sicily and Calabria (Italy). Participants completed self-report measures assessing parental monitoring, psychological control, coping strategies (i.e., TaskOriented, Emotion-Oriented, and Avoidance-Oriented). Results of the path analysis showed that coping strategies play a mediating role in the association between parental psychological control and both adolescents' anxiety and drinking behavior. Furthermore, a direct positive association was reported from parental psychological control and anxiety, while a negative direct association was reported from parental monitoring to drinking behavior. Results of this study provide a comprehensive model that showed that the different coping strategies could explain the psychological mechanisms that underline the associations between two different kinds of parental control (psychological control and monitoring) and both internalizing and externalizing adolescents' form of maladjustment (e.g. anxiety and drinking behaviors). Overall, coping strategies seem to be a fruitful target for the prevention programs for adolescents' anxiety and drinking behaviors.
\end{abstract}

Keywords Parental control $\cdot$ Coping $\cdot$ Anxiety $\cdot$ Drinking behavior $\cdot$ Adolescence

Cristiano Inguglia

cristiano.inguglia@unipa.it; cristianoinguglia@gmail.com

Sebastiano Costa

sebastiano.costa@unicampania.it

Sonia Ingoglia

sonia.ingoglia@unipa.it

Francesca Cuzzocrea

francesca.cuzzocrea@unime.it

Francesca Liga

ligaf@unime.it

1 Dipartimento di Scienze Psicologiche, Pedagogiche, dell'Esercizio Fisico e della Formazione, Università degli Studi di Palermo, Viale delle Scienze, Ed.15, 90128 Palermo, Italy

2 Dipartimento di Psicologia, Università degli studi della Campania Luigi Vanvitelli, Caserta, Italy

3 Dipartimento di Scienze della Salute, Università degli Studi "Magna Graecia" di Catanzaro, Catanzaro, Italy

4 Dipartimento di Medicina Clinica e Sperimentale, Università degli Studi di Messina, Messina, Italy
Several studies provide evidence that parental control plays an important role in the lives of adolescents (Bean et al. 2006; Lamborn and Felbab 2003; Hoeve et al. 2009; Kincaid et al. 2011). This parenting dimension was shown to be associated to adolescents' problem behaviors, such as anxiety and drinking behaviors (Gugliandolo et al. 2015; Inguglia et al. 2015; Kincaid et al. 2011; Romm and Metzger 2018; Soenens et al. 2012). However, the mechanisms that underline these relationships are still unexplored, and coping strategies could play a relevant mediating role. Hence, the present study tries to enhance the knowledge of the role of both parental control and coping strategies on the onset of adolescents' problem behaviors, in terms of anxiety and drinking behaviors.

\section{Two Forms of Parental Control: Parental Monitoring and Psychological Control}

According to Amato (1990) "parental control is reflected in the number of decisions parents make, the amount of supervision they exercise, and the number of rules they hold for their children" (p. 613). The relationship between parental control and adolescents' psychological functioning has been an ongoing 
issue for scholars (Bean et al. 2006; Criss et al. 2015). Although some authors have considered control as an aspect of positive and effective parenting (Criss et al. 2015; Laird et al. 2003; Tilton-Weaver et al. 2013), others have examined control as an indicator of negative and overbearing parenting (Bean et al. 2006; Costa et al. 2016; Inguglia et al. 2016).

To better understand the concept of parental control, some authors have differentiated it into two kinds: behavioral and psychological (Barber 1996; Bean et al. 2006; Garber et al. 1997; Gray and Steinberg 1999; Soenens et al. 2010). In particular, according to Bean et al. (2006), parental behavioral control or monitoring "refers to the provision of regulation or structure on the child's behavioral world" (p. 1336). Instead, according to Ingoglia et al. (2017) "psychological control is the tendency to pressure children to comply with parents' agenda through insidious and manipulative tactics, such as guilt induction, shaming, and love withdrawal" (p. 1228).

In light of the distinction between these constructs, it is interesting to analyze the effects of each form of parental control on adolescents' problem behaviors. For this purpose, a review of the studies on this topic are presented separately for each type of parental control.

\section{Parental Monitoring and Adolescents' Problem Behaviors}

A number of studies have analyzed the associations of parental monitoring with adolescents' problem behaviors, showing that is usually related to low levels of both internalizing and externalizing problem behaviors (Arata et al. 2003; Bean et al. 2006; Criss et al. 2015; Kunz and Grych 2013; Laird et al. 2003; Lansford et al. 2014; Yap and Jorm 2015). Internalizing and externalizing problem behaviors are two empirically derived dimensional constructs that have been used frequently to operationalize adolescent behavioral problems (Achenbach and Rescorla 2001). While internalizing problem behaviors are characterized primarily by processes within the self (i.e., anxiety, depression, and somatization), externalizing problem behaviors are characterized primarily by actions in the external world, such as acting out, antisocial behavior, hostility, and aggression (Achenbach et al. 2002).

Parental monitoring was found to be linked to low levels of problem behaviors both internalizing and externalizing in adolescence. In particular, there is extant evidence that parental monitoring is associated with lower levels of internalizing problem behaviors, like depression and anxiety, in youth (Hamza and Willoughby 2011; Jacobson and Crockett 2000; Restifo and Bögels 2009; Stattin and Kerr 2000; Yap and Jorm 2015). For instance, Yap and Jorm (2015) performed a systematic review of parental factors related to anxiety and depression among youths, showing that increased parental monitoring is linked to reduced risk for such internalizing problematic behaviors. However, while the negative relationship between parental monitoring and adolescents' depression is more evident in the literature, the link with anxiety is less evident, with some studies reporting negative associations (Bacchini et al. 2011; Yap and Jorm 2015), and others reporting non-significant or positive associations (Pettit et al. 2001; Yap and Jorm 2015). For this reason, the current study focuses on this specific outcome.

Furthermore, parental monitoring was also shown to be negatively related to externalizing problem behaviors like antisocial behavior (Criss et al. 2015), cigarette smoking (Chuang et al. 2005), drug use (Shillington et al. 2005), gambling and delinquency (Vitaro et al. 2001), vandalism (Miller and Plant 2003), and alcohol use (Arata et al. 2003; Capaldi et al. 2009; Latendresse et al. 2008). In particular, parental monitoring seems to play an important protective role with regard to the prevention of drinking behaviors. For instance. Arata et al. (2003), in a sample of 930 high school students, using a set of self-report measures, have found that problem drinkers reported less parental monitoring than their peers who do not drink or drink less.

\section{Parental Psychological Control and Adolescents' Problem Behaviors}

Parental psychological control, instead, has been generally shown to negatively impact adolescents' lives in terms of high levels of internalizing and externalizing problem behaviors (Bean et al. 2006; Criss et al. 2015; Cui et al. 2014; Kunz and Grych 2013; Inguglia et al. 2016; Laird et al. 2003; Lansford et al. 2014; Mabbe et al. 2015). In particular, the relationships between parental psychological control and adolescents' internalizing difficulties, such as depressive symptoms and anxiety, has been investigated by several researchers (Inguglia et al. 2016; Soenens et al. 2010). Research has shown that parents who use psychological control, limit children's attempts to gain independence, as they view such attempts as a danger for their relationship with their sons/daughters. Moreover, controlling parents tend to demand perfection and high performance from their children (Ingoglia et al. 2017; Xiang and Liu 2018). As a result of these restrictions, youths tend to develop high levels of anxiety, especially during adolescence, when the demands for autonomy are relevant (Barber 1996; Chorpita and Barlow 1998; Liga et al., 2015; Pettit et al. 2001; Schleider et al. 2014). According to Chorpita and Barlow (1998), parenting styles marked by high psychological control may reduce children's abilities to explore new environments and enhance their feelings of hypervigilance and fear, leading to the onset of anxiety.

The associations between psychological control and externalizing problems is less studied because some authors have indicated that psychological control seems to have more marked effects on the onset of internalizing problems instead of externalizing problems (Soenens et al. 2010). However, 
other scholars have reported that psychological control may lead to externalizing difficulties, such as conduct problems, antisocial behavior, and drinking behaviors in adolescence (Batanova and Loukas 2014; Hoeve et al. 2009; León-DelBarco et al. 2019; Liga et al. 2017; Pinquart 2017). According to Georgiou and Symeou (2018), considering that adolescents strive for increased autonomy and independence, they may perceive the attempts of parents to exert psychological control over their own lives as intrusive and inappropriate, thus youth may try to escape from this situation by engaging in externalizing behaviors (Galambos et al. 2003). In particular, drinking alcohol can represent a way to escape from psychologically controlling parents in adolescence (Galambos et al. 2003; Pinquart 2017; Romm and Metzger 2018). For instance, Romm and Metzger (2018), in a study involving 161 adolescents living in US, showed that high levels of parental psychological control were linked to more frequent drinking behaviors. However, few studies have analyzed specifically the relationships between parental psychological control and drinking behavior. For this reason, the present paper takes into account this dimension as an outcome variable.

\section{Parental Control and Adolescents' Problem Behavior: The Role of Coping Strategies}

Although several studies have confirmed that the two kinds of parental control have direct impact on adolescents' problem behaviors (Bean et al. 2006; Cui et al. 2014; Yap and Jorm $2015)$ these associations have been also shown to be mediated by other variables (Criss et al. 2015; Cui et al. 2014; Finkenauer et al. 2005). According to some scholars, coping strategies are a mediator to analyze (Folkman and Lazarus 1988; Moran et al. 2018). For instance, attachment theory (Bowlby 1973) and related studies have found substantial evidence that the association between parent-child relationship and psychological adaptation indices may be mediated by coping and emotion regulation (e.g., Contreras et al. 2000). Other studies have provided empirical support that healthy coping strategies mediate the association of positive parenting with adjustment in adulthood (e.g., Holahan et al. 1995).

Coping strategies refer to activities that are carried out to master or minimize the impact of perceived threats or challenges (Lazarus and Folkman 1984). Lazarus and Folkman (1984) consider coping as a dynamic process that results in the management of the internal and external demands that are assessed as challenging or exceeding individuals' resources. The stress is not produced by the specific event, but by the perception of one's lack of resources to cope with the stressful event (Compas et al. 2001; Liga et al. 2020; Lohman and Jarvis 2000).

In their classic work, Lazarus and Folkman (1984) differentiated two main kinds of coping strategies, the problemfocused and the emotion-focused. The first kind of strategies aim to resolve the stressful event, whereas the second kind of strategies aim to manage the emotions arising during the stressful situation instead of modifying the situation itself. Endler and Parker $(1990,1994)$ identified three basic coping strategies, namely, task-oriented, emotion-oriented, and avoidance-oriented coping. The first two strategies are similar to those proposed by Lazarus and Folkman (1984). Taskoriented coping is focused on problems and concerns taking direct action to solve or minimize the effects of a stressful situation in order to lessen the stress it evokes. For instance, it involves focusing on the problem, planning solutions, seeking information or assistance in handling the situation, or choosing an alternative. Emotion-oriented coping involves efforts to reframe the stressful situation so that it no longer elicit negative emotions and prolong stress. Rather than taking actions to change the stressor itself, the individual tries to control feelings using a variety of cognitive and behavioral tools (e.g., by distancing, isolating, self-preoccupation, fantasy, or wishful thinking). Finally, the avoidance coping refers to the attempts to deny, minimize, or avoid dealing directly with stressful episodes. For instance, by escaping the problem, distancing oneself, or engaging in unrelated activities, in order to lessen the perception of stress (Holahan et al. 2005). Several authors (Compas et al. 2014; Herres and Ohannessian 2015; Pisanti et al. 2015) have shown that task-oriented coping is more effective than the other two strategies because has beneficial effects and provides optimal results.

Empirical support was found for an association between parental control and coping (Chen et al. 2016; Nijhof and Engels 2007). In particular, some studies framed on Self-Determination Theory (SDT; Ryan and Deci 2000) argue that parental psychological control is associated with children's coping strategies (Chen et al. 2016; Inguglia et al. 2020; Nijhof and Engels 2007; Wolfradt et al. 2003). For instance, Chen et al. (2016) found that need frustration related to controlling parenting may elicit responses that vary from avoidance to emotional responses, including the expression of emotions, self-blame, emotion inhibition and passive acquiescence, in order to escape from the control of parents to reduce the stress related to the control they exert.

Instead, the authors who analyzed the associations between parental monitoring and children's coping strategies (Chen et al. 2016; Romero and Ruiz 2007) have underlined that parental monitoring is related to more adaptive coping strategies, such as task-oriented (i.e., trying to negotiate in order to reach a constructive solution). In this sense parental monitoring could provide a structure to develop task-oriented coping and reduce the risk to promote maladaptive coping strategies (Meesters and Muris 2004; Wolfradt et al. 2003). This association was explained by Meesters and Muris (2004) in line with previous work demonstrating that a parenting style characterized by firmness, monitoring and supportiveness, is related to 
positive developmental outcomes in adolescence, including more active coping.

Coping strategies are also associated with adolescents' problems behaviors. There is evidence that adolescents who show the ability to use coping strategies that are appropriate to face the demanding situations display more adaptive outcomes, whereas teens who use less appropriate coping strategies have been reported to show poorer psychological functioning (Markova and Nikitskaya 2017; Modecki et al. 2017; Skinner and Zimmer-Gembeck 2007). In general, several studies have found that active coping such as task-oriented strategies is associated with higher psychological well-being, as well as low levels of both internalizing and externalizing problems during adolescence (Compas et al. 2014; Krattenmacher et al. 2013; Modecki et al. 2017; Undheim and Sund 2017). The reason for the beneficial effects of this form of coping probably could be explained by the fact that it intervenes directly on the cause of the problem, changing or eliminating the source of the stress in an active way, and using new strategies and instrumental social support (Lohman and Jarvis 2000).

The use of avoidance-oriented strategies is generally associated with adolescents' poor adaptation and high levels of problem behaviors, including drinking behaviors (Creswell et al. 2015; Krattenmacher et al. 2013; Undheim and Sund 2017). In fact, avoidance-oriented coping often exacerbates stress because it doesn't help individuals to deal with the things that are causing them stress. Instead, it includes denying that the stressful event occurred or its impact, physically removing oneself from the situation, and escaping through the use of alcohol or drugs (Britton 2004; Lohman and Jarvis 2000).

Finally, the use of emotion-oriented coping seems to be related to negative outcomes (Undheim and Sund 2017). Some studies report that it is associated with internalizing problems, like depression and anxiety (Billings and Moos 1985; Hampel and Petermann 2006), and other studies show that it is related to drinking behaviors (Goldstein et al. 2012). According to some authors, emotion-focused coping may lead to an intensification of emotional distress, partially because individuals are more focused on the emotional experience rather than finding problem-solving strategies to deal with the stressful event (Sears, Urizar, \& Evans, 2000). When there is no constructive affect-regulation, emotion-oriented coping can result in excessive concern with negative emotions (e.g., suppression, self-blame, and rumination; Parker and Endler 1996). Thus, individuals who use this strategy may report higher levels of depression and anxiety (McWilliams et al. 2003; Sears et al. 2000).

\section{The Present Study}

The existing findings that have been described in the previous sections seem unsatisfactory in explaining the associations between the two kinds of parental control, coping strategies and problem behaviors in adolescence. Therefore, the current study sought to contribute to shedding more light on this topic. In particular, the study was intended to analyze the role of parental monitoring, parental psychological control, and coping strategies on adolescents' problem behaviors, in terms of anxiety and drinking behavior.

The theoretical framework of the study integrates different theories. First, it refers to the theories of parental monitoring and psychological control (e.g., Bean et al. 2006; Barber 1996; Lionetti et al, 2018; Soenens et al. 2010) that highlight the positive effects of parental monitoring on children's anxiety and drinking behavior, while underlining the potential negative impact of psychological control on the these specific outcomes. Second, the study is based on the definition of coping strategies developed by Endler and Parker (1990, 1994) who distinguish three basic coping strategies, namely task-oriented, emotion-oriented, and avoidance-oriented coping, and considers task-oriented coping as the most adaptive compared to the other two strategies. Third, the study refers to the attachment theory (Bowlby 1973) and related research (Contreras et al. 2000) highlighting that coping may mediate the association of parenting with children's adaptation. Fourth, it is also based on the Self-Determination Theory (SDT; Ryan and Deci 2000) arguing that the experience of controlling parenting may elicit inappropriate coping strategies (such as emotionoriented and avoidance-oriented) and may be negatively associated with task-oriented strategies (Chen et al. 2016).

Starting from this theoretical background, the current study was aimed at testing, through a path analysis with the integration of bootstrapping, an integrate model in which parental psychological control and parental monitoring predict coping strategies that in turn predict anxiety and drinking behavior. In line with previous research, a negative association between parental monitoring and psychological control was expected. Furthermore, it was expected that parental psychological control would be positively linked to avoidance and emotion-oriented strategies, and negatively associated with task-oriented strategies. On the contrary, it was expected that parental monitoring would be negatively related with avoidance and emotion-oriented strategies, and positively associated with task-oriented strategies. Moreover, it was hypothesized that avoidance and emotion-oriented strategies would be positively related to both adolescents' anxiety and drinking behavior, whereas task-oriented strategies would be negatively related to both adolescents' anxiety and drinking behavior. Finally, it was predicted that parental monitoring and parental psychological control would be linked 
to both adolescents' anxiety and drinking behavior through the mediating effect of the coping strategies.

\section{Method}

\section{Participants}

The participants of the study were 541 (282 male and 248 female -10 did not report this information) high school students aged from 16 to 18 years $(M=17.09 ; \mathrm{DS}=0.80)$. All the participants were Italian speaking students who attended high school in Sicily and Calabria (Italy). Regarding parental education, the majority of participants reported that their fathers and mothers obtained a high school diploma ( $45 \%$ of father, $48 \%$ of mothers), $28 \%$ of participants declared that their father had a secondary school diploma, $21 \%$ that their father obtained a college or university degree, $3 \%$ reported that their father obtained a primary school certification, while $3 \%$ did not report this information. Regarding the education of the participants' mothers, $31 \%$ of participants reported that their mothers obtained a secondary school diploma, $18 \%$ reported that their mothers obtained a university degree, $1 \%$ of participants declared that their mothers had a primary school certification, while $2 \%$ did not report this information.

\section{Procedure}

This convenient sample was recruited contacting Italian high schools. Informed consent for participation in the present study was provided by the parents of the students. Participants completed the questionnaire in their classrooms, in a single session lasting about $30 \mathrm{~min}$. Instructions stated that the questionnaires were voluntary and confidential treatment of the data was guaranteed. Instruments of this study were selected because they represent the most widely used evaluation methods for the operationalization of the constructs examined.

\section{Instruments}

Parental Psychological Control The Psychological Control Scale-Youth Self-Report (PCS-YSR; Barber 1996 was used to evaluate parental psychological control. This questionnaire consists of 8 items (sample item: 'My mother/father is always trying to change how I feel or think about things') with a 3point Likert-type scale ranging from 1 'not like her (him)' to 3 'a lot like her (him)'. Participants answered separately for their mother and father. A composite psychological control score was computed by averaging the maternal and paternal scores. This procedure was already widely used (Brenning et al. 2012) and was warranted by the significant correlation between both ratings $(\mathrm{r}=.39 ; p<.01)$. This scale has good psychometric characteristics in different cultural contexts as shown by previous studies (Barber et al. 2005), and in the present study the scale has acceptable internal reliabilities (Table 1).

Parental Monitoring The five-item parental monitoring scale (Stattin and Kerr 2000) was used for the estimation of parental monitoring. Participants were asked to rate how much their parents know about their activities (e.g. "Do your parents know where you are most afternoons after school") using a 3 point rating scale from 1 (almost never) to 3 (very often). The scale did not differentiate by mother/father but provided a general score for both parents. Previous studies (Bean et al. 2006) have broadly used this scale, that has acceptable internal reliabilities (Table 1).

Coping Strategies Coping strategies were evaluated with the Coping Inventory for Stressful Situations (CISS; Endler and Parker 1999) that is a self-report instrument of 48 items on a five point Likert-type rating scale that ranges from 1 (Not at all) to 5 (Very much). This scale is composed by three subscale each defined by 16 -item scales: Task-oriented coping

Table 1 Descriptive and correlation analyses

\begin{tabular}{|c|c|c|c|c|c|c|c|c|c|c|c|c|c|}
\hline & $\alpha$ & Min & Max & M & SD & Sym & Kur & 1 & 2 & 3 & 4 & 5 & 6 \\
\hline 1. Psychological control & .75 & 1.00 & 2.75 & 1.58 & .30 & .50 & .23 & & & & & & \\
\hline 2. Parental monitoring & .73 & 1.00 & 3.00 & 2.59 & .39 & -1.10 & 1.32 & $-.23^{* *}$ & & & & & \\
\hline 3.Emotion & .86 & 1.06 & 4.75 & 2.78 & .72 & .07 & -.45 & $.30^{* *}$ & .02 & & & & \\
\hline 4.Task & .86 & 1.38 & 5.00 & 3.51 & .61 & .00 & -.15 & -.01 & .05 & -.05 & & & \\
\hline 5.Avoidance & .86 & 1.19 & 5.00 & 3.01 & .76 & -.09 & -.57 & $.11^{*}$ & .02 & $.28^{* * *}$ & $.20^{* *}$ & & \\
\hline 6.Drinking behavior & .81 & .00 & 36.00 & 4.47 & 4.88 & 1.87 & 5.18 & $.15^{* *}$ & $-.30^{* *}$ & .01 & -.01 & $.14^{* *}$ & \\
\hline 7.Anxiety & .92 & 1.00 & 3.75 & 2.19 & .59 & .34 & -.52 & $.25^{* *}$ & .01 & $.59^{* *}$ & $-.26^{* *}$ & -.02 & $-.09^{*}$ \\
\hline
\end{tabular}

${ }^{*} p<.05 ;{ }^{* *} p<.01$ 
(Task scale), Emotion-oriented coping (Emotion scale), and Avoidance-oriented coping (Avoidance scale). In this study, the scale has acceptable internal reliabilities (Table 1).

Anxiety State The State Trait Anxiety Inventory (STAI; Spielberger et al. 1983), is a self-report instrument that is composed by 20 items (e.g., "I am tense") assessing the state anxiety. Participants had to specify their agreement with each statement using a 5-point scale ( $1=$ a very bad description of me; $5=$ a very good description of me). The scale had adequate internal consistency (Table 1).

Audit Alcohol Consumption was assessed with the Alcohol Use Disorders Identification Test (AUDIT; Babor et al. 2001). The scale is composed of ten items assessing the amount and frequency of drinking, and the problems related to alcohol abuse. Participants were asked to indicate on a five-point scale, ranging from 0 (never) to 4 (frequently or daily), how often the behaviors occur. In the current study, a total score for alcohol consumption based on these items was computed. The scale reached adequate internal consistency (Table 1).

\section{Data Analysis}

The Mplus software was used to conduct the analysis of this study, and in line with the Preacher and Hayes' (2008) bootstrapping approach 5000 bootstrap replication samples and $95 \%$ bias corrected confidence intervals were applied to estimate direct, total, and indirect effects (Preacher and Hayes 2008; Wu and Jia 2013; Shrout and Bolger 2002). A significant specific indirect effect designates that the effect of the predictor variables influenced the criterion variables occurred through that particular mediator. Gender was included as a background variable, to verify if the association between variables is significant after controlling for gender. In fact, some studies showed that parental control, coping, and problem behaviors are also conditioned by gender (Bekker and van Mens-Verhulst 2007; Borawski et al. 2003; De Matos et al. 2008; Tamres et al. 2002).

\section{Results}

\section{Descriptive Statistics, Internal Reliability, and Correlation}

In order to present the analysis that was conducted on the data, the descriptive statistics, Cronbach's alpha values and correlations for all variables were reported in Table 1. Correlations showed that parental psychological Control and Parental Monitoring were negatively related, and that Parental Psychological Control was positively related with Emotion coping strategy, Avoidance coping strategy, Drink Behavior and Anxiety, while Parental Monitoring was negatively related with Drink Behavior. Emotion coping strategy was positively related with Avoidance coping strategy and with Anxiety, while Task coping strategy positively related with Avoidance coping strategy, and negatively related with Anxiety. Finally, Drink Behavior was positively related with Avoidance coping strategy, but was negatively related with Anxiety.

\section{Mediation Model}

In order to examine the mediation role of Coping Strategies (Task, Emotion, and Avoidance) on the relations from parental perception of Psychological Control and Parental Monitoring to Anxiety and Drinking Behavior, a path analysis was conducted. Estimation of the saturated model (Fig. 1), and therefore no fit indices were reported, showed significant paths from Parental Psychological Control to Avoidance-oriented Coping $(\beta=.12, p<.05)$ and to Emotion-oriented Coping $(\beta=.31, p<.05)$. Furthermore, Drinking Behavior was
Fig. 1 - Structural relationships between studies variables. Note: Coefficients shown are standardized path coefficients. Dotted lines represent negative relations

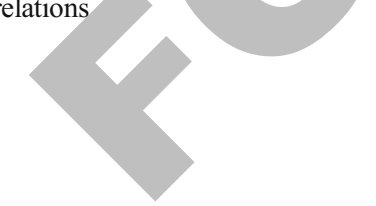

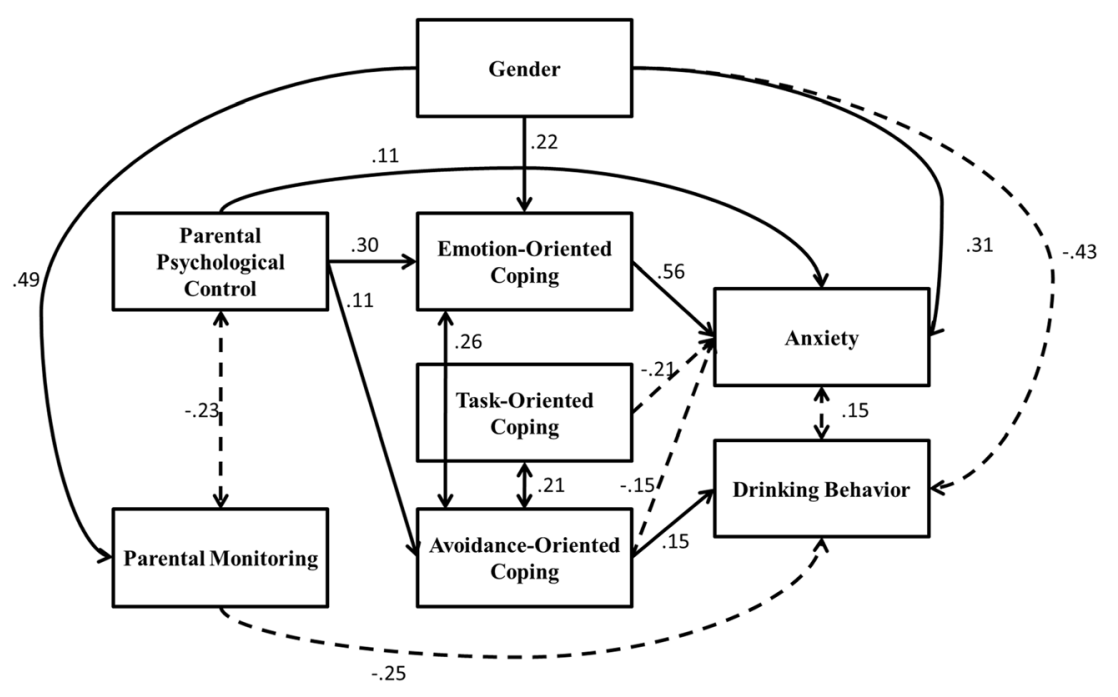


positively predicted by Avoidance-oriented Coping ( $\beta=.15$, $p<.05)$ and negatively by Parental Monitoring $(\beta=-.23$, $p<.05)$. Anxiety, instead, was positively predicted by Parental Psychological Control $(\beta=.10, p<.05)$, and by Emotion-oriented Coping $(\beta=.56, p<.05)$, while Anxiety was negatively predicted by Task-oriented Coping $(\beta=-.20$, $p<.05)$, and Avoidance-oriented Coping $(\beta=-.15, p<.05)$. Finally Gender had a direct effect on Parental Monitoring $(\beta=.50, p<.05)$, Emotion-oriented Coping $(\beta=.47$, $p<.05)$, Drinking Behavior $(\beta=-.43, p<.05)$, Anxiety $(\beta=.31 ; p<.05)$

A trimming procedure was used to test the saturated model, removing all nonsignificant paths (e.g., Pedhazur 1997) and resting the model several indices showed that the data well fit the final model (Fig. 1), $\chi 2(13)=11.92, p>.05, \mathrm{CFI}=1.00$, SRMR $=.02$, RMSEA $=.00(90 \% \mathrm{CI}=.00-.04)$. Similarity to the saturated model, significant paths from Parental Psychological Control to Avoidance-oriented Coping $(\beta=.11, p<.05)$ and to Emotion-oriented Coping $(\beta=.30$, $p<.05)$. Furthermore, Drinking Behavior was positively predicted by Avoidance-oriented Coping $(\beta=.15, p<.05)$ and negatively by Parental Monitoring $(\beta=-.25, p<.05)$. Anxiety, instead, was positively predicted by Parental Psychological Control $(\beta=.11, p<.05)$, and by Emotionoriented Coping ( $\beta=.56, p<.05$ ), while Anxiety was negatively predicted by Task-oriented Coping $(\beta=-.20, p<.05)$, and Avoidance-oriented Coping $(\beta=-.15, p<.05)$. Finally Gender had a direct effect on Parental Monitoring $(\beta=.49$, $p<.05)$, Emotion-oriented Coping $(\beta=.46, p<.05)$, Drinking Behavior $(\beta=-.43, p<.05)$, Anxiety $(\beta=.31$; $p<.05)$. Examination of the total, direct and indirect paths from Parental Psychological Control and Monitoring to Anxiety and Drinking Behavior whilst controlling for coping strategies were examined (Table 2). A statistically significant indirect association between Drinking Behavior and Parental
Psychological Control through Avoidance -oriented Coping $(\beta=.02, p<.05)$. Furthermore, a significant indirect association between Parental Psychological Control and Anxiety through Avoidance-oriented Coping $(\beta=-.04, p<.05)$, and through Emotion-oriented Coping $(\beta=.11, p<.05)$. Finally a direct effect from Parental Monitoring to Drink Behavior $(\beta=$ $-.25, p<.05)$, and from Parental Psychological Control to Anxiety $(\beta=.11, p<.05)$.

\section{Discussion}

The current study sought to enhance the knowledge about the relationships between the two forms of parental control, coping strategies and problem behaviors in adolescence. In particular, the study was aimed to analyze the role of parental monitoring, parental psychological control, and coping strategies on adolescents' problem behayiors, in terms of anxiety and drinking behavior. The results for each hypothesis are presented and discussed separately below.

Firstly, the prediction that parental monitoring and psychological control would be negatively associated with each other was confirmed by the results. This is consistent with some studies underlining that parental monitoring and psychological control are different constructs that describe two distinct forms of parental control and are negatively correlated. The main difference between these constructs lies in the fact that parental monitoring is characterized by efforts to manage or monitor the behavior of children via guidelines, clear rules, restrictions, and structures (Akcinar and Baydar 2014; Aunola and Nurmi 2005; Shek 2007; Symeou and Georgiou 2017), while psychological control is characterized by behaviors aimed at limiting and manipulating children's emotional states like making them feel guilty or anxious (Akcinar and Baydar 2014; Aunola and Nurmi 2005; Soenens et al. 2010).
Table 2 Path estimates, SEs and 95\% CIs for models with direct effect and indirect effect

\begin{tabular}{|c|c|c|c|c|}
\hline 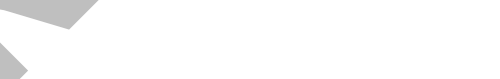 & $\beta$ & $\begin{array}{l}\text { Lower bound (BC) } \\
95 \% \text { CI }\end{array}$ & $\begin{array}{l}\text { Upperbound (BC) } \\
95 \% \text { CI }\end{array}$ & $\mathrm{p}$ \\
\hline \multicolumn{5}{|l|}{ Direct effect } \\
\hline $\begin{array}{c}\text { Parental Monitoring } \rightarrow \\
\text { Drinking Behavior }\end{array}$ & -.25 & -.34 & -.16 & $<.001$ \\
\hline $\begin{array}{l}\text { Parental Psychological } \\
\text { Control } \rightarrow \text { Anxiety }\end{array}$ & .11 & .04 & .18 & $<.001$ \\
\hline \multicolumn{5}{|l|}{$\begin{array}{l}\text { Indirect effect via avoidance- } \\
\text { oriented coping }\end{array}$} \\
\hline $\begin{array}{l}\text { Parental Psychological } \\
\text { Control } \rightarrow \text { Anxiety }\end{array}$ & -.02 & -.03 & -.01 & .03 \\
\hline $\begin{array}{l}\text { Parental Psychological } \\
\text { Control } \rightarrow \text { Drinking Behavior }\end{array}$ & .02 & .01 & .03 & .02 \\
\hline \multicolumn{5}{|l|}{ Indirect effect via emotion-oriented coping } \\
\hline Parental Psychological Control $\rightarrow$ Anxiety & .17 & .12 & .22 & $<.001$ \\
\hline
\end{tabular}

BC 95\% CI = Bias Corrected-Confidence Interval 
Secondly, support was found for the hypothesis that parental psychological control is linked to the use of less effective coping strategies (Benoit Allen et al. 2016; Cui et al. 2014; Luebbe et al. 2014). In fact, psychological control was positively associated with emotion-oriented and avoidanceoriented coping. Thus, the more adolescents experience constraint or manipulation by their parents, the more they use coping strategies that are based on the management of the emotions occurring during the stressful event, or on avoiding dealing with it, rather than coping strategies aimed at resolving the stressful situation (Endler and Parker 1994; Golpelwar 2014). This is in line with the previsions of Chen et al. (2016) stating that the perception of being psychologically controlled by parents may elicit behaviors like avoidance or emotional responses in attempt to escape from the control of parents. However, differently to what was assumed, psychological control is not related to a reduced use of effective coping strategies since no significant negative associations between psychological control and task-oriented coping came to light. One possible explanation is that, for the teens of our sample, their parent's controlling behavior is perceived as unmanageable, as something they are not able to change though negotiation or through problem-solving techniques. Hence, they make use of less direct coping strategies in order to cope with the stressful situation and try to manage it (Benoit Allen et al. 2016).

Moreover, in line with the predictions of the study, avoidance-oriented coping was positively and significantly associated with adolescent's drinking behavior, whereas differently from the hypothesis, it was negatively related to anxiety state. Findings also confirmed that emotion-oriented coping was positively and significantly related to anxiety state but contrary to what expected it was not significantly related to drinking behaviors.

When considered together, these findings confirm that less effective coping strategies are likely to be linked to negative outcomes in adolescence (Markova and Nikitskaya 2017; Modecki et al. 2017). However, when examined in details some differences in the relationships between coping strategies and adolescents' problem behavior come to light. The coping strategy based on avoidance seems to be linked to the use of alcohol, since drinking behaviors may represent a mean to run away or regulate unpleasant emotions related to a stressful situation without trying to change it (Compas et al. 2001; Windle and Windle 1996). This way, avoidance is used trying to refuse the reality of the stressful event. At the same time, this kind of strategy is linked to lower levels of anxiety, probably because the possibility to run away from the stressful situation without facing the parents directly and demanding less control from them is perceived as slightly anxiogenic by the teens. This finding is not consistent with that of other studies showing that avoidance coping is associated with anxiety (Gomez and McLaren 2006; Seiffge-Krenke 2000).
However, research also suggests that in some situations the use of avoidant strategies may be associated with lower anxiety because such strategies allow teens to focus on more positive episodes of their life when nothing or little can be done to change the stressful situation (Herres and Ohannessian 2015).

Furthermore, in our sample, emotion-oriented coping seems to be directly related only to anxiety and not to drinking behavior. The first kind of association was already shown by several authors (Rafnsson et al. 2006; Smith et al. 2016) who have underlined the strict connections between coping strategies based on emotion and the expression of internalizing difficulties like anxiety states. In some cases, emotionoriented coping may result in excessive concern with negative emotions (e.g., suppression, self-blame, and rumination; Parker and Endler 1996), and this can be associated with higher levels of depression and anxiety (McWilliams et al. 2003; Sears Jr. et al. 2000). Moreover, although the emotion-oriented strategies were shown to be linked to substance use and alcohol consumption as well (Eitle and Eitle 2014), our data does not provide evidence for a direct association between these variables. Instead, as it will be noted below, the emotion-oriented strategies play a mediating role in the indirect association between parental psychological control and drinking behavior.

With regard to the hypothesis that task-oriented strategies would be negatively related to both adolescents' problem behaviors, data partly confirmed the predictions because taskoriented coping was negatively and significantly related only to anxiety and not to drinking behavior. The lack of correlation between task-oriented coping and drinking behavior was reported also in previous studies (Creech and Borsari 2014; Rafnsson et al. 2006) that confirm that people could use alcohol as coping strategy, predominantly to avoid negative distress and as consequence of failure to cope with the negative emotions (Fromme and Rivet 1994).

Moreover, no support was provided for the mediating role of coping strategies in the associations of parental monitoring with adolescents' anxiety and drinking behavior. Data showed a direct and negative relationship between parental monitoring and youth drinking behavior. In line with previous studies (Arata et al. 2003; Capaldi et al. 2009; Latendresse et al. 2008), the provision of regulation or structure by parents seems to be associated with a lower likelihood of problematic alcohol use of children during adolescence. However, contrary from what expected, data did not show that coping strategies play a mediating role in these associations. One possible explanation is that coping strategies are elicited by stressful situations, such as psychologically controlling parenting that thwarts the satisfaction of children's basic psychological needs (Chen et al. 2016), while they are not triggered by parental monitoring that is supposed to serve a positive socializing function for children (Symeou and Georgiou 2017). 
In line with the previous explanations, we found a certain support that coping strategies mediates the association of psychological control with adolescents' anxiety and drinking behavior. Specifically, parental psychological control was shown to be partly associated with both adolescents' anxiety and drinking behavior both directly and indirectly through the mediating effect of the coping strategies. Parental psychological control had direct effect on anxiety. Moreover, data showed a significant indirect association between parental psychological control and drinking behavior through the mediation of avoidance-oriented coping. Additionally, significant indirect associations between parental psychological control and anxiety through both avoidance-oriented and emotion-oriented coping were reported.

Such findings confirm that parental psychological control is related to problem behaviors during adolescence (Cui et al. 2014; Plunkett et al. 2007; Symeou and Georgiou 2017), especially in terms of internalizing difficulties like anxiety. As stated by several authors (Inguglia et al. 2018; Xiang and Liu 2018), parents who use psychological control tend to limit children's attempts to gain independence and this parenting pattern may enhance children's anxiety by increasing their avoidance of challenging events (Barber 1996; Van der Bruggen et al. 2010).

Moreover, some results support the prediction that coping strategies may play a mediating role in these associations. In particular, both emotion-oriented and avoidance-oriented coping strategies seem to mediate the relationship between psychological control and adolescents' problem behaviors, even though they do in different ways. Specifically, the perception of psychological control by parents seems to be associated with emotion-oriented coping that, in turn, is linked to higher levels of both anxiety and drinking behavior. In this case, data confirms the work of Chen et al. (2016). In the attempt to face the stress related to the perception of parental psychological control, youths use emotion-oriented strategies that are inappropriate to reduce the stress linked to the situation and therefore are associated with negative outcomes in terms of feelings of anxiety and drinking behaviors.

Instead, the psychological control is associated with avoidance-oriented coping that, in turn, is related to lower levels of anxiety. Thus, it is likely that avoidance coping may allow adolescents to reject, at least temporarily, the reality of the stress related to controlling behaviors exerted by parents, reducing the anxiety potentially associated with this experience. Perhaps this "escape attempt" from the stressful experience can be linked at a later stage to other problem behaviors, like it could be seen considering the direct association between avoidance coping and the drinking behavior already discussed above. In this mediating process, task-oriented coping did not seem to have an important role, maybe because in this kind of stressful situation teens assume that it would be very difficult to take direct actions to alter the situation itself in light of the asymmetrical relationship between them and their parents, thus they prefer adopting alternative strategies, even if dysfunctional, like those based on avoidance or emotion. Another possible explanation could be the fact that some other parental practices could have a stronger effect on task-oriented coping. For example, studies based on SDT (Costa et al. 2019; Ryan and Deci 2017; Skinner et al. 2005) reported that parental structure - defined as the extent to which family context provides children with information and guidance about the ways to achieve desirable outcomes and to avoid undesired outcomes (Skinner et al. 2005) - has a main role in the satisfaction of the need of competence. Considering that taskoriented coping is a coping strategy that needs competence in order to manage stressful situations, it is plausible that parental structure could show a positive relation with it. Future studies could try to test this suggestion.

Finally, this study found direct associations of gender with parental monitoring, emotion-oriented coping, drinking behavior, and anxiety. These findings are in line with previous studies which have reported that females tend to perceive more monitoring from their parents (Borawski et al. 2003), make use of more emotion-oriented strategies (Tamres et al. 2002), have a lower drinking behavior (De Matos et al. 2008), and show higher scores of anxiety (Bekker and van MensVerhulst 2007) than males.

This study has potential limitations. First, its crosssectional design precludes us from clearly inferring the direction of the relationships among the study variables. Therefore, future longitudinal studies are needed in order to allow researchers to conclude about the direction of the relationships among these variables. Second, future research should employ a multi-informant methodology including reports of parents because the study was based only on adolescents' self-reports and this can represent a limit (Inguglia et al. 2016). Third, the current study did not assess how coping strategies may vary in relation to the situational context. According to Heffer and Willoughby (2017) this makes it "extremely difficult to evaluate and account for varying subjective stressors, as well as dispositional and environmental factors, in order to identify an objective measure of how coping may be adaptive in response to specific contexts" (p. 12). Further studies should help to better understand the role of the context in the relationship between coping strategies and adjustment.

Despite these shortcomings, the study represents one attempt to analyze a relatively understudied issue, such as the mediation of coping strategies in the associations between parental monitoring and psychological control with adolescents' problem behaviors in terms of anxiety and drinking behavior. To our knowledge it is the first research that takes into account in a comprehensive model the two forms of parental control, coping strategies, adolescents' anxiety and drinking behaviors. Moreover, the study provides evidence 
to the literature affirming that the adaptive qualities of coping strategies should be assessed in the specific stressful situation in which they occur (Tuncay et al. 2008).

Finally, the findings of our study have practical implications because they provide suggestions for developing training programs addressed to both adolescents and their parents. Particularly, results seem to suggest that programs should train teens at effectively managing their coping strategies in different situations, especially when they face stress related to controlling parenting, to thwart the onset of problem behaviors. Moreover, programs should target enhancing parents' awareness of the importance of the use of monitoring strategies and the avoidance of psychologically controlling parenting in preventing children's problem behaviors. According to Inguglia et al. (2020) parents should be equipped with skills to keep an eye on their children's activities and relationships without being invasive. This probably would help them to recognize when their children are at risk to develop problem behaviors and to promptly and properly intervene (Inguglia et al. 2020; Symeou and Georgiou 2017).

\section{Compliance with Ethical Standards}

Conflict of Interest On behalf of all authors, the corresponding author states that there is no conflict of interest.

Ethical Statements The data from this paper have not been previously presented. My coauthors and I do not have any interests that might be interpreted as influencing the research, and the ethical standards of APA were followed in the conduct of the study. In particular, the research was performed in accordance with the declaration of Helsinki and was approved by local ethics committee. Furthermore, informed consent to participate in the study was obtained from participants and/or their parents.

\section{References}

Achenbach, T. M., \& Rescorla, L. A. (2001). Manual for the ASEBA school-age forms and profiles. Burlington: University of Vermont Research Center for Children, Youth, \& Families.

Achenbach, T. M., Dumenci, L., \& Rescorla, L. A. (2002). Ten-year comparisons of problems and competencies for national samples of youth: Self, parent, and teacher reports. Journal of Emotional and Behavioral Disorders, 10, 194-203. https://doi.org/10.1177/ 10634266020100040101.

Akcinar, B., \& Baydar, N. (2014). Parental control is not unconditionally detrimental for externalizing behaviors in early childhood. International Journal of Behavioral Development, 38, 118-127. https://doi.org/10.1177/0165025413513701.

Amato, P. (1990). Dimensions of the family environment as perceived by children: A multidimensional scaling analysis. Journal of Marriage and Family, 52, 613-620. https://doi.org/10.2307/352928.

Arata, C. M., Stafford, J., \& Tims, M. S. (2003). High school drinking and its consequences. Adolescence, 38, 567-579.

Aunola, K., \& Nurmi, J. E. (2005). The role of parenting styles in children's problem behavior. Child Development, 76, 1144-1159. https://doi.org/10.1111/j.1467-8624.2005.00841.x.

Babor, T. F., Biddle-Higgins, J. C., Saunders, J. B., \& Monteiro, M. G. (2001). AUDIT: The alcohol use disorders identification test:
Guidelines for use in primary health care. Geneva: World Health Organization.

Bacchini, D., Miranda, M. C., \& Affuso, G. (2011). Effects of parental monitoring and exposure to community violence on antisocial behavior and anxiety/depression among adolescents. Journal of Interpersonal Violence, 26(2), 269-292. https://doi.org/10.1177/ 0886260510362879.

Barber, B. K. (1996). Parental psychological control: Revisiting a neglected construct. Child Development, 67, 3296-3319. https:// doi.org/10.1111/j.1467-8624.1996.tb01915.x.

Barber, B. K., Stolz, H., Olsen, J., Collins, W. A., \& Burchinal, M. (2005). Parental support, psychological control, and behavioral control: Assessing relevance across time, culture and method. Monographs of the Society for Research in Child Development, 70(4), 1-147. https://doi.org/10.1111/j.1540-5834.2005.00365.x.

Batanova, M., \& Loukas, A. (2014). Unique and interactive effects of empathy, family, and school factors on early adolescents' aggression. Journal of Youth and Adolescence, 43, 1890-1902. https://doi. org/10.1007/s10964-013-0051-1.

Bean, R. A., Barber, B. K., \& Crane, D. R. (2006). Parental support, behavioral control, and psychological control among African American youth. Journal of Family Issues, 27, 1335-1355. https:// doi.org/10.1177/0192513X06289649.

Bekker, M. H. J., \& van Mens-Verhulst, J. (2007). Anxiety disorders: Sex differences in prevalence, degree and background, but genderneutral treatment. Gender Medicine, 4, 178-193. https://doi.org/ 10.1016/S1550-8579(07)80057-X.

Benoit Allen, K., Silk, J.S., Meller, S., Tan, P.Z., Ladouceur, C.D., Sheeber, L.B., \&, Ryan, N. D. (2016). Parental autonomy granting and child perceived control: Effects on the everyday emotional experience of anxious youth. Journal of Child Psychology and Psychiatry, 57, 835-842. doi: https://doi.org/10.1111/jcpp.12482.

Billings, A. G., \& Moos, R. H. (1985). Psychosocial stressors, coping and depression. In E. E. Beckham \& W. R. Leber (Eds.), Handbook of depression: treatment, assessment and research. Homewood: Dorsey Press.

Borawski, E. A., Ievers-Landis, C. E., Lovegreen, L. D., \& Trapl, E. S. (2003). Parental monitoring, negotiated unsupervised time, and parental trust: The role of perceived parenting practices in adolescent health risk behaviors. Journal of Adolescent Health, 33, 60-70. https://doi.org/10.1016/S1054-139X(03)00100-9.

Bowlby, J. (1973). Attachment and loss: Vol. 2. Separation: Anxiety and anger. New York: Basic Books.

Brenning, K., Soenens, B., Braet, C., \& Bosmans, G. (2012). Attachment and depressive symptoms in middle childhood and early adolescence: Testing the validity of the emotion regulation model of attachment. Personal Relationships, 19, 445-464. https://doi.org/10. 1111/j.1475-6811.2011.01372.x.

Britton, P. C. (2004). The relation of coping strategies to alcohol consumption and alcohol-related consequences in a college sample. Addiction Research \& Theory, 12, 103-114. https://doi.org/10. 1080/16066350310001613062.

Capaldi, D. M., Stoolmiller, M., Kim, H. K., \& Yoerger, K. (2009). Growth in alcohol use in at-risk adolescent boys: Two-part random effects prediction models. Drug and Alcohol Dependence, 105, 109-117. https://doi.org/10.1016/j.drugalcdep.2009.06.013.

Chen, B., Soenens, B., Vansteenkiste, M., Van Petegem, S., \& Beyers, W. (2016). Where do the cultural differences in dynamics of controlling parenting lie? Adolescents as active agents in the perception of and coping with parental behavior. Psychologica Belgica, 56, 169-192. https://doi.org/10.5334/pb.306.

Chorpita, B. F., \& Barlow, D. H. (1998). The development of anxiety: The role of control in the early environment. Psychological Bulletin, 124, 3-21. https://doi.org/10.1037/0033-2909.124.1.3.

Chuang, Y.-C., Ennett, S. T., Bauman, K. E., \& Foshee, V. A. (2005). Neighborhood influences on adolescent cigarette and alcohol use: 
Mediating effects through parent and peer behaviors. Journal of Health and Social Behavior, 46, 187-204. https://doi.org/10.1177/ 002214650504600205 .

Compas, B. E., Connor-Smith, J. K., Saltzman, H., Thomsen, A. H., \& Wadsworth, M. (2001). Coping with stress during childhood and adolescence: Progress, problems, and potential. Psychological Bulletin, 127, 87-127. https://doi.org/10.1037//0033-2909.127.1. 87.

Compas, B. E., Jaser, S. S., Dunbar, J. P., Watson, K. H., Bettis, A. H., Gruhn, M. A., \& Williams, E. K. (2014). Coping and emotion regulation from childhood to early adulthood: Points of convergence and divergence. Australian Journal of Psychology, 66, 71-81. https://doi.org/10.1111/ajpy.12043.

Contreras, J. M., Kerns, K. A., Weimer, B. L., Gentzler, A. L., \& Tomich, P. L. (2000). Emotion regulation as a mediator of associations between mother-child attachment and peer relationships in middle childhood. Journal of Family Psychology, 14, 111-124. https://doi. org/10.1037/0893-3200.14.1.111.

Costa, S., Hausenblas, H. A., Oliva, P., Cuzzocrea, F., \& Larcan, R. (2016). The role of age, gender, mood states and exercise frequency on exercise dependence. Journal of Behavioral Addictions, 2, 216223. https://doi.org/10.1556/JBA.2.2013.014.

Costa, S., Sireno, S., Larcan, R., \& Cuzzocrea, F. (2019). The six dimensions of parenting and adolescent psychological adjustment: The mediating role of psychological needs. Scandinavian Journal of Psychology, 60, 128-137. https://doi.org/10.1111/sjop.12507.

Creech, S. K., \& Borsari, B. (2014). Alcohol use, military sexual trauma, expectancies, and coping skills in women veterans presenting to primary care. Addictive Behaviors, 39, 379-385. https://doi.org/10. 1016/j.addbeh.2013.02.006.

Creswell, K. G., Chung, T., Wright, A. G., Clark, D. B., Black, J. J., \& Martin, C. S. (2015). Personality, negative affect coping, and drinking alone: A structural equation modeling approach to examine correlates of adolescent solitary drinking. Addiction, 110, 775-783. https://doi.org/10.1111/add.12881.

Criss, M. M., Lee, T. K., Morris, A. S., Cui, L., Bosler, C. D., Shreffler, K. M., \& Silk, J. S. (2015). Link between monitoring behavior and adolescent adjustment: An analysis of direct and indirect effects. Journal of Child and Family Studies, 24, 668-678. https://doi.org/ 10.1007/s10826-013-9877-0.

Cui, L., Morris, A. S., Criss, M. M., Houltberg, B. J., \& Silk, J. (2014). Parental psychological control and adolescent adjustment: The role of adolescent emotion regulation. Parenting: Science and Practice, 14, 47-67. https://doi.org/10.1080/15295192.2014.880018.

De Matos, M. G., Gaspar, T., Simons-Morton, B., Reis, M., \& Ramiro, L. (2008). Communication and information about "safer sex": Intervention issues within communities of African migrants living in poorer neighbourhoods in Portugal. Journal of Poverty, 12, 333350. https://doi.org/10.1080/10875540802198628.

Eitle, T. M., \& Eitle, D. J. (2014). Race, coping strategies, and substance use behaviors: A preliminary analysis examining white and American Indian adolescents. Substance Use \& Misuse, 49, 315 325. https://doi.org/10.3109/10826084.2013.832329.

Endler, N. S., \& Parker, J. D. A. (1990). Multidimensional assessment of coping: A critical evaluation. Journal of Personality and Social Psychology, 58, 844-854. https://doi.org/10.1037/0022-3514.58.5. 844.

Endler, N. S., \& Parker, J. D. A. (1994). Assessment of multidimensional coping: Task, emotions, and avoidance strategies. Psychological Assessment, 6, 50-60. https://doi.org/10.1037/1040-3590.6.1.50.

Endler, N. S., \& Parker, J. D. A. (1999). Coping inventory for stressful situations (CISS): Manual (2nd ed.). Toronto: Multi-Health Systems.

Finkenauer, C., Frijns, T., Engels, R. C. M. E., \& Kerkhof, P. (2005). Perceiving concealment in relationships between parents and adolescents: Links with parental behavior. Personal Relationships, 12, 387-406. https://doi.org/10.1111/j.1475-6811.2005.00122.x.

Folkman, S., \& Lazarus, R. S. (1988). Manual for the ways of coping questionnaire (Research ed.). Palo Alto: Consulting Psychologists Press.

Fromme, K., \& Rivet, K. (1994). Young adults' coping style as a predictor of their alcohol use and response to daily events. Journal of Youth and Adolescence, 23(1), 85-97. https://doi.org/10.1007/ BF01537143.

Galambos, N. L., Barker, E. T., \& Almeida, D. M. (2003). Parents do matter: Trajectories of change in externalizing and internalizing problems in early adolescence. Child Development, 74, 578-594. https://oi.org/10.1111/1467-8624.7402017.

Garber, J., Robinson, N. S., \& Valentiner, D. (1997). The relation between parenting and adolescent depression: Self-worth as a mediator. Journal of Adolescent Research, 12, 12-33. https://doi.org/10. 1177/0743554897121003.

Georgiou, S. N. \& Symeou, M. (2018). Parenting practices and the development of internalizing/ externalizing problems in adolescence. In L. Benedetto \& M. Ingrassia (Eds.), Parenting - Empirical Advances and Intervention Resources, IntechOpen. https://doi.org/ 10.5772/66985. Available from: https://www.intechopen.com/ books/parenting-empirical-advances-and-intervention-resources/ parenting-practices-and-the-development-of-internalizingexternalizing-problems-in-adolescence

Goldstein, A. L., Vilhena-Churchill, N., Stewart, S. H., \& Wekerle, C. (2012). Coping motives as moderators of the relationship between emotional distress and alcohol problems in a sample of adolescents involved with child welfare. Advances in Mental Health, 11, 67-75. https://doi.org/10.5172/jamh.2012.11.1.67.

Golpelwar, M. (2014). Action and cognition in task oriented coping: Factor structure and internal consistency of the CISS-21 with an Indian sample. Peer J PrePrints, 2, e519v2. https://doi.org/10. 7287/peerj.preprints.519v2.

Gomez, R., \& McLaren, S. (2006). The association of avoidance coping style, and perceived mother and father support with anxiety/ depression among late adolescents: Applicability of resiliency models. Personality and Individual Differences, 40, 1165-1176. https://doi.org/10.1016/j.paid.2005.11.009.

Gray, M. R., \& Steinberg, L. (1999). Unpacking authoritative parenting: Reassessing a multidimensional construct. Journal of Marriage and Family, 61(3), 574-587. https://doi.org/10.2307/353561.

Gugliandolo, M. C., Costa, S., Cuzzocrea, F., \& Larcan, R. (2015). Trait emotional intelligence as mediator between psychological control and behaviour problems. Journal of Child and Family Studies, 24(8), 2290-2300. https://doi.org/10.1007/s10826-014-0032-3.

Hampel, P., \& Petermann, F. (2006). Perceived stress, coping, and adjustment in adolescents. Journal of Adolescent Health, 38, 409-415. https://doi.org/10.1016/j.jadohealth.2005.02.014.

Hamza, C. A., \& Willoughby, T. (2011). Perceived parental monitoring, adolescent disclosure, and adolescent depressive symptoms: A longitudinal examination. Journal of Youth and Adolescence, 40(7), 902-915. https://doi.org/10.1007/s10964-010-9604-8.

Heffer, T., \& Willoughby, T. (2017). A count of coping strategies: A longitudinal study investigating an alternative method to understanding coping and adjustment. PLoS One, 12, e0186057. https:// doi.org/10.1371/journal.pone.0186057.

Herres, J., \& Ohannessian, C. M. (2015). Adolescent coping profiles differentiate reports of depression and anxiety symptoms. Journal of Affective Disorders, 186, 312-319. https://doi.org/10.1016/j.jad. 2015.07.031.

Hoeve, M., Dubas, J. S., Eichelsheim, V. I., Laan, P. H., Smeenk, W. H., \& Gerris, J. R. M. (2009). The relationship between parenting and delinquency: A meta-analysis. Journal of Abnormal Child Psychology, 37, 749-775. https://doi.org/10.1007/s10802-0099310-8. 
Holahan, C. J., Valentiner, D. P., \& Moos, R. H. (1995). Parental support, coping strategies, and psychological adjustment: An integrative model with late adolescents. Journal of Youth and Adolescence, 24, 633-648. https://doi.org/10.1007/BF01536948.

Holahan, C. J., Moos, R. H., Holahan, C. K., Brennan, P. L., \& Schutte, K. K. (2005). Stress generation, avoidance coping, and depressive symptoms: A 10-year model. Journal of Consulting and Clinical Psychology, 73, 658-666. https://doi.org/10.1037/0022-006X.73.4. 658.

Ingoglia, S., Inguglia, C., Liga, F., \& Lo, C. A. (2017). Associations between perceived parental psychological control and internalizing difficulties in emerging adulthood: The role of identity. Journal of Social and Personal Relationships, 34, 1227-1240. https://doi.org/ 10.1177/0265407516670760.

Inguglia, C., Ingoglia, S., Liga, F., Lo, C. A., \& Lo Cricchio, M. G. (2015). Autonomy and relatedness in adolescence and emerging adulthood: Relationships with parental support and psychological distress. Journal of Adult Development, 22, 1-13. https://doi.org/ 10.1007/s10804-014-9196-8.

Inguglia, C., Ingoglia, S., Liga, F., Lo Coco, A., Lo Cricchio, M. G., Musso, P., et al. (2016). Parenting dimensions and internalizing difficulties in Italian and U.S. emerging adults: The intervening role of autonomy and relatedness. Journal of Child and Family Studies, 25, 419-431. https://doi.org/10.1007/s10826-015-0228-1.

Inguglia, C., Liga, F., Lo Coco, A., Musso, P., \& Ingoglia, S. (2018). Satisfaction and frustration of autonomy and relatedness needs: Associations with parenting dimensions and psychological functioning. Motivation and Emotion, 42, 691-705. https://doi.org/10.1007/ s11031-018-9702-6.

Inguglia, C., Costa, S., Ingoglia, S., \& Liga, F. (2020). Associations between peer pressure and adolescents' binge behaviors: The role of basic needs and coping. The Journal of Genetic Psychology, 180, 144-155. https://doi.org/10.1080/00221325.2019.1621259.

Jacobson, K. C., \& Crockett, L. (2000). Parental monitoring and adolescent adjustment: An ecological perspective. Journal of Research on Adolescence, 10, 65-97. https://doi.org/10.1207/SJRA1001_4.

Kincaid, C., Jones, D. J., Cuellar, J., \& Gonzalez, M. (2011). Psychological control associated with youth adjustment and risky behavior in African American single mother families. Journal of Child and Family Studies, 20, 102-110. https://oi.org/10.1007/ s10826-010-9383-6.

Krattenmacher, T., Kühne, F., Führer, D., Beierlein, V., Brähler, E., Resch, F., et al. (2013). Coping skills and mental health status in adolescents when a parent has cancer: A multicenter and multiperspective study. Journal of Psychosomatic Research, 74, 252259. https://doi.org/10.1016/j.jpsychores.2012.10.003.

Kunz, J. H., \& Grych, J. H. (2013). Parental psychological control and autonomy granting: Distinctions and associations with child and family functioning. Parenting: Science and Practice, 13, 77-94. https://doi.org/10.1080/15295192.2012.709147.

Laird, R. D., Pettit, G. S., Bates, J. E., \& Dodge, K. A. (2003). Parents' monitoring-relevant knowledge and adolescents' delinquent behavior: Evidence of correlated developmental changes and reciprocal influences. Child Development, 74, 752-768. https://doi.org/10. 1111/1467-8624.00566.

Lamborn, S. D., \& Felbab, A. J. (2003). Applying ethnic equivalence and cultural values models to African-American teens' perceptions of parents. Journal of Adolescence, 26, 601-618. https://doi.org/10. 1016/S0140-1971(03)00059-9.

Lansford, J. E., Laird, R. D., Pettit, S., Bates, J. E., \& Dodge, K. A. (2014). Mothers' and fathers' autonomy-relevant parenting: Longitudinal links with adolescents' externalizing and internalizing behavior. Journal of Youth and Adolescence, 43, 1877-1889. https://doi.org/10.1007/s10964-013-0079-2 .

Latendresse, S. J., Rose, R. J., Viken, R. J., Pulkkinen, L., Kaprio, J., \& Dick, D. M. (2008). Parenting mechanisms in links between parents' and adolescents' alcohol use behaviors. Alcoholism: Clinical and Experimental Research, 32, 322-330. https://doi.org/10.1111/j. 1530-0277.2007.00583.x.

Lazarus, R. S., \& Folkman, S. (1984). Stress, appraisal, and coping. New York: Springer

León-Del-Barco, B., Mendo-Lázaro, S., Polo-Del-Río, M. I., \& LópezRamos, V. M. (2019). Parental psychological control and emotional and behavioral disorders among Spanish adolescents. International Journal of Environmental Research and Public Health, 16, 507. https://doi.org/10.3390/ijerph16030507.

Liga, F., Ingoglia, S., Lo Cricchio, M. G., \& Lo Coco, A. (2015). Mothers' parenting stress and adolescents' emotional separation: The role of youngsters' self orientation. International Journal of Developmental Science, 9, 147-156. https://doi.org/10.3233/DEV150169.

Liga, F., Ingoglia, S., Inguglia, C., Lo Coco, A., Lo Cricchio, M. G., Musso, P., Cheah, C., Rose, L., \& Gutow, M. (2017). Associations among psychologically controlling parenting, autonomy, relatedness, and problem behaviors during emerging adulthood. The Journal of Psychology: Interdisciplinary and Applied, 151, 393 415. https://doi.org/10.1080/00223980.2017.1305323.

Liga, F., Inguglia, C., Gugliandolo, C., Ingoglia, S., \& Costa, S. (2020). The socialization of coping strategies in adolescence: The modeling role of parents. Anxiety, Stress, \& Coping, 33, 47-58. https://doi.org/ 10.1080/10615806.2019.1666248.

Lionetti, F., Palladino, B. E., Passini, C. M., Casonato, M., et al. (2018). The development of parental monitoring during adolescence: A meta-analysis. European Journal of Developmental Psychology. https://doi.org/10.1080/17405629.2018.1476233.

Lohman, B. J., \& Jarvis, P. A. (2000). Adolescent stressors, coping strategies, and psychological health studied in the family context. Journal of Youth and Adolescence, 29, 15-43. https://doi.org/10. 1023/A:1005117020812.

Luebbe, A. M., Bump, K. A., Fussner, L. M., \& Rulon, K. J. (2014). Perceived maternal and paternal psychological control: Relations to adolescent anxiety through deficits in emotion regulation. Child Psychiatry \& Human Development, 45(5), 565-576. https://doi. org/10.1007/s10578-013-0425-3.

Mabbe, E., Soenens, B., Vansteenkiste, M., \& Van Leeuwen, K. (2015). Do personality traits moderate relations between psychologically controlling parenting and problem behavior in adolescents? Journal of Personality, 84, 381-392. https://doi.org/10.1111/jopy. 12166.

Markova, S., \& Nikitskaya, E. (2017). Coping strategies of adolescents with deviant behavior. International Journal of Adolescence and Youth, 22, 36-46. https://doi.org/10.1080/02673843.2013.868363.

McWilliams, L. A., Cox, B. J., \& Enns, M. W. (2003). Use of the coping inventory for stressful situations in a clinically depressed sample: Factor structure, personality correlates, and prediction of distress. Journal of Clinical Psychology, 59, 423-437. https://doi.org/10. 1002/jclp.10080.

Meesters, C., \& Muris, P. (2004). Perceived parental rearing behaviours and coping in young adolescents. Personality and Individual Differences, 37, 513-522. https://doi.org/10.1016/j.paid.2003.09. 022.

Miller, P., \& Plant, M. (2003). The family, peer influences and substance use: Findings from a study of UK teenagers. Journal of Substance Use, 8, 19-26. https://doi.org/10.1080/1465989021000067209.

Modecki, K. L., Zimmer-Gembeck, M. J., \& Guerra, N. (2017). Emotion regulation, coping, and decision making: Three linked skills for preventing externalizing problems in adolescence. Child Development, 88, 417-426. https://doi.org/10.1111/cdev.12734.

Moran, K. M., Turiano, N. A., \& Gentzler, A. L. (2018). Parental warmth during childhood predicts coping and well-being in adulthood. Journal of Family Psychology. https://doi.org/10.1037/ fam0000401. 
Nijhof, S., \& Engels, R. (2007). Parent styles, coping strategies, and the expression of homesickness. Journal of Adolescence, 30, 709-720. https://doi.org/10.1016/j.adolescence.2006.11.009.

Parker, J. D. A., \& Endler, N. S. (1996). Coping and defense: A historical overview. In M. Zeidner \& N. S. Endler (Eds.), Handbook of coping: Theory, research, applications (pp. 3-23). Oxford, England: Wiley.

Pedhazur, E. J. (1997). Multiple regression in behavioral research: Explanation and prediction. New York: Thompson Learning. Inc.

Pettit, G. S., Laird, R. D., Bates, J. E., Dodge, K. A., \& Criss, M. M. (2001). Antecedents and behavior-problem outcomes of parental monitoring and psychological control in early adolescence. Child Development, 72, 583-598. https://doi.org/10.1111/1467-8624. 00298.

Pinquart, M. (2017). Associations of parenting dimensions and styles with externalizing problems of children and adolescents: An updated meta-analysis. Developmental Psychology, 53, 873-932. https://doi.org/10.1037/dev0000295.

Pisanti, R., van der Doef, M., Maes, S., Lombardo, C., Lazzari, D., \& Violani, C. (2015). Occupational coping self-efficacy explains distress and well-being in nurses beyond psychosocial job characteristics. Frontiers in Psychology, 6, 1143. https://doi.org/10.3389/fpsyg. 2015.01143.

Plunkett, W. S., Henry, S. C., Robinson, C., Behnke, A., \& Falcon III, C. (2007). Adolescent perception of parental behaviors, adolescent self-esteem, and adolescent depressed mood. Journal of Child Family Studies, 16, 760-772. https://doi.org/10.1007/s10826-0069123-0.

Preacher, K. J., \& Hayes, A. F. (2008). Asymptotic and resampling strategies for assessing and comparing indirect effects in multiple mediator models. Behavior Research Methods, 40, 879-891. https://doi. org/10.3758/BRM.40.3.879.

Rafnsson, F. D., Jonsson, F. H., \& Windle, M. (2006). Coping strategies, stressful life events, problem behaviors, and depressed affect. Anxiety Stress and Coping, 19, 241-257. https://doi.org/10.1080/ 10615800600679111.

Restifo, K., \& Bögels, S. M. (2009). Family risk factors for youth depression: A family systems integration and treatment model. Clinical Psychology Review, 29, 294-316. https://doi.org/10.1016/j.cpr. 2009.02.005.

Romero, A. J., \& Ruiz, M. (2007). Does familism lead to increased parental monitoring? Protective factors for coping with risky behaviors. Journal of Child and Family Studies, 16(2), 143-154. https:// doi.org/10.1007/s10826-006-9074-5.

Romm, K., \& Metzger, A. (2018). Parental psychological control and adolescent problem behaviors: The role of depressive symptoms. Journal of Child and Family Studies, 27, 2206-2216. https://doi. org/10.1007/s10826-018-1064-x.

Ryan, R. M., \& Deci, E. L. (2000). Self-determination theory and the facilitation of intrinsic motivation, social development, and wellbeing. American Psychologist, 55, 68-78. https://doi.org/10.1037/ 0003-066X.55.1.68.

Ryan, R. M., \& Deci, E. L. (2017). Self-determination theory: Basic psychological needs in motivation, development, and wellness. New York: Guilford Press.

Schleider, J. L., Vélez, C. E., Krause, E. D., \& Gillham, J. E. (2014). Perceived psychological control and anxiety in early adolescents: The mediating role of attributional style. Cognitive Therapy and Research, 38, 71-81. https://doi.org/10.1007/s10608-013-9573-9.

Sears Jr., S. F., Urizar Jr., G. G., \& Evans, G. D. (2000). Examining a stress-coping model of burnout and depression in extension agents. Journal of Occupational Health Psychology, 5, 56-62. https://doi. org/10.1037/1076-8998.5.1.56.

Seiffge-Krenke, I. (2000). Causal links between stressful events, coping style, and adolescent symptomatology. Journal of Adolescence, 23, 675-691. https://doi.org/10.1006/jado.2000.0352.
Shek, D. T. (2007). A longitudinal study of perceived parental psychological control and psychological well-being in Chinese adolescents in Hong Kong. Journal of Clinical Psychology, 63, 1-22. https://doi. org/10.1002/jclp.20331.

Shillington, A., Lehman, S., Clapp, J., Hovell, M., Sipan, C., \& Blumberg, E. (2005). Parental monitoring: Can it continue to be protective among high-risk adolescents? Journal of Child \& Adolescent Substance Abuse, 15, 1-15. https://doi.org/10.1300/ J029v15n01_01.

Shrout, P. E., \& Bolger, N. (2002). Mediation in experimental and nonexperimental studies: New procedures and recommendations. Psychological Methods, 7, 422-445. https://doi.org/10.1037// 1082-989X.7.4.422.422.

Skinner, E. A., \& Zimmer-Gembeck, M. J. (2007). The development of coping. Annual Review of Psychology, 58, 119-144. https://doi.org/ 10.1146/annurev.psych.58.110405.085705.

Skinner, E., Johnson, S., \& Snyder, T. (2005). Six dimensions of parenting: A motivational model. Parenting: Science and Practice, 5, 175-235. https://doi.org/10.1207/s15327922par0502 3.

Smith, M., Saklofske, D., Keefer, K., \& Tremblay, P. F. (2016). Coping strategies and psychological outcomes: The moderating effects of personal resiliency. The Journal of Psychology. Interdisciplinary and Applied, 150, 318-332. https://doi.org/10.1080/00223980. 2015.1036828

Soenens, B., Vansteenkiste, M., \& Luyten, P. (2010). Toward a domainspecific approach to the study of parental psychological control: Distinguishing between dependency-oriented and achievement oriented psychological control. Journal of Personality, 78, 217-256. https://doi.org/10.1111/j.1467-6494.2009.00614.x.

Soenens, B., Park, S.-Y., Vansteenkiste, M., \& Mouratidis, A. (2012). Perceived parental psychological control and adolescent depressive experiences: A cross-cultural study with Belgian and south-Korean adolescents. Journal of Adolescence, 35, 261-272. https://doi.org/ 10.1016/j.adolescence.2011.05.001.

Spielberger, C. D., Gorsuch, R. L., Lushene, R. E., Lushene, R., Vagg, P. R., \& Jacobs, G. A. (1983). Manual for the state-trait anxiety inventory. Palo Alto: Consulting Psychologist Press.

Stattin, H., \& Kerr, M. (2000). Parental monitoring: A reinterpretation. Child Development, 71, 1072-1085. https://doi.org/10.1111/14678624.00210.

Symeou, M., \& Georgiou, S. (2017). Externalizing and internalizing behaviours in adolescence, and the importance of parental behavioural and psychological control practices. Journal of Adolescence, 60 , 104-113. https://doi.org/10.1016/j.adolescence.2017.07.007.

Tamres, L. K., Janicki, D., \& Helgeson, V. S. (2002). Sex differences in coping behavior: A meta-analytic review and an examination of relative coping. Personality and Social Psychology Review, 6, 230. https://doi.org/10.1207/S15327957PSPR0601_1.

Tilton-Weaver, L. C., Burk, W. J., Kerr, M., \& Stattin, H. (2013). Can parental monitoring and peer management reduce the selection or influence of delinquent peers? Testing the question using a dynamic social network approach. Developmental Psychology, 49, 20572070. https://doi.org/10.1037/a0031854.

Tuncay, T., Musabak, I., Gok, D. E., \& Kutlu, M. (2008). The relationship between anxiety, coping strategies and characteristics of patients with diabetes. Health and Quality of Life Outcomes, 6, 79. https:// doi.org/10.1186/1477-7525-6-79.

Undheim, A. M., \& Sund, A. M. (2017). Associations of stressful life events with coping strategies of 12-15-year-old Norwegian adolescents. European Child and Adolescent Psychiatry., 26, 993-1003. https://doi.org/10.1007/s00787-017-0979-x.

Van der Bruggen, C. O., Bögels, S. M., \& van Zeilst, N. (2010). What influences parental controlling behaviour? The role of parent and child trait anxiety. Cognition and Emotion, 24, 141-149. https:// doi.org/10.1080/02699930802618843. 
Vitaro, F., Brendgen, M., Ladouceur, R., \& Tremblay, R. E. (2001). Gambling, delinquency, and drug use during adolescence: Mutual influences and common risk factors. Journal of Gambling Studies, 17, 171-190. https://doi.org/10.1023/A:1012201221601.

Windle, M., \& Windle, R. C. (1996). Coping strategies, drinking motives, and stressful life events among adolescents: Associations with behavioral and emotional problems, and academic functioning. Journal of Abnormal Psychology, 105, 551-560. https://doi.org/ 10.1037/0021-843X.105.4.551.

Wolfradt, U., Hempel, S., \& Miles, J. (2003). Perceived parenting styles, depersonalization, anxiety and coping behavior in adolescents. Personality and Individual Differences, 34, 521-532. https://doi. org/10.1016/S0191-8869(02)00092-2.

$\mathrm{Wu}, \mathrm{W} .$, \& Jia, F. (2013). A new procedure to test mediation with missing data through nonparametric bootstrapping and multiple imputation.
Multivariate Behavioral Research, 48, 663-691. https://doi.org/10. 1080/00273171.2013.816235.

Xiang, S., \& Liu, Y. (2018). Understanding the joint effects of perceived parental psychological control and insecure attachment styles: A differentiated approach to adolescent autonomy. Personality and Individual Differences, 126, 12-18. https://doi.org/10.1016/j.paid. 2018.01.009.

Yap, M. B., \& Jorm, A. F. (2015). Parental factors associated with childhood anxiety, depression, and internalizing problems: A systematic review and meta-analysis. Journal of Affective Disorders, 175, 424440. https://doi.org/10.1016/j.jad.2015.01.0.

Publisher's Note Springer Nature remains neutral with regard to jurisdictional claims in published maps and institutional affiliations.

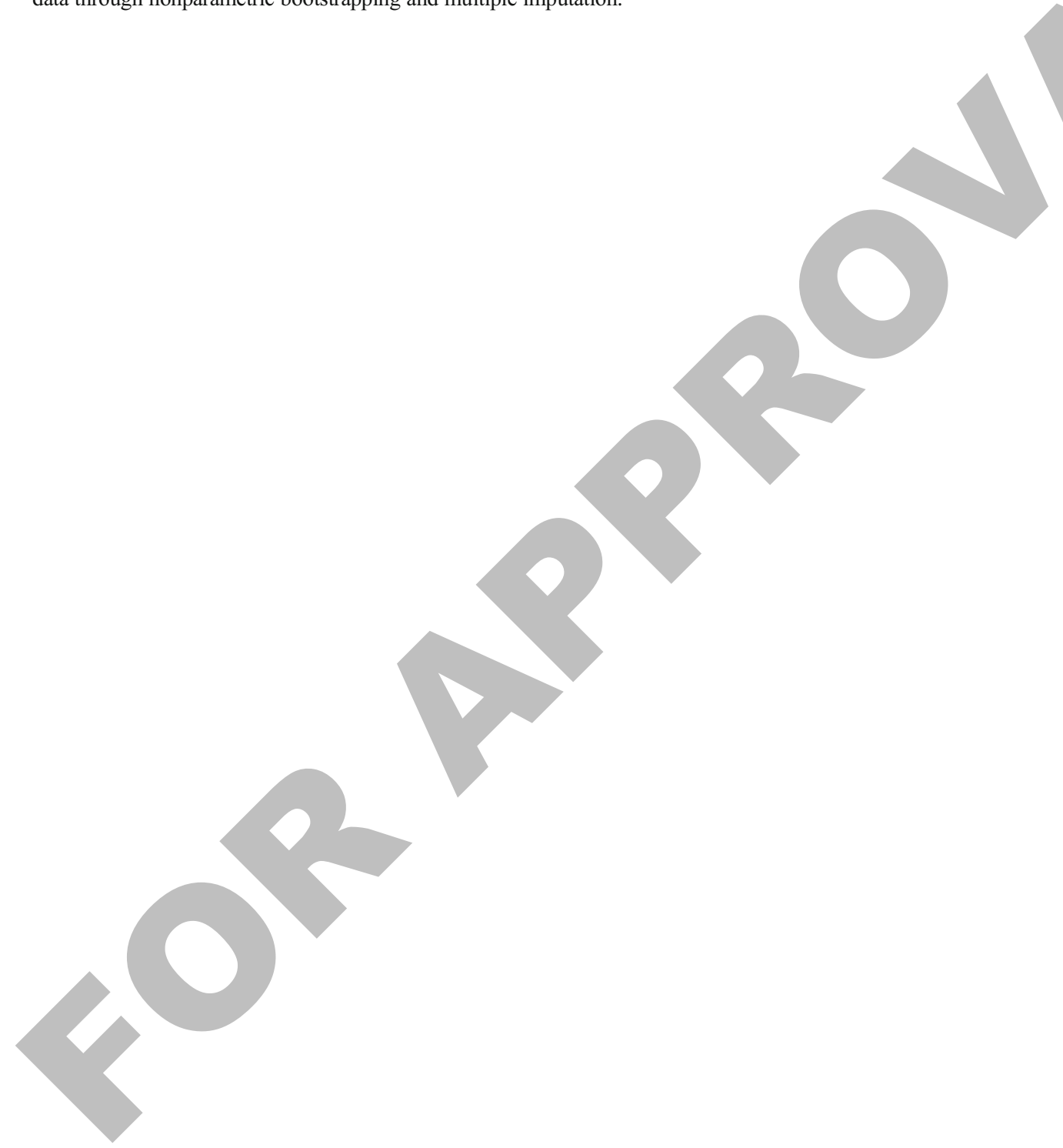

